\title{
BILANGAN STRONG RAINBOW CONNECTION UNTUK GRAF GARIS, GRAF MIDDLE DAN GRAF TOTAL
}

\author{
MARADONA \\ Program Studi Magister Matematika, \\ Fakultas Matematika dan Ilmu Pengetahuan Alam, Universitas Andalas, \\ Kampus UNAND Limau Manis Padang, Indonesia. \\ email : maradonacool07@gmail.com
}

\begin{abstract}
Abstrak. Misalkan $G=(V(G), E(G))$ adalah suatu graf terhubung tak trivial. Definisi pewarnaan $c: E(G) \rightarrow\{1,2, \cdots, k\}, k \in N$, dimana dua sisi yang bertetangga boleh berwarna sama. Suatu lintasan $u-v$ path $P$ di $G$ dinamakan rainbow path jika tidak terdapat dua sisi di $P$ yang berwarna sama. Graf $G$ disebut rainbow connected jika setiap dua titik yang berbeda di $G$ dihubungkan oleh rainbow path. Pewarnaaan sisi yang menyebabkan $G$ bersifat rainbow connected dikatakan rainbow coloring. Bilangan rainbow connection dari graf terhubung $G$, ditulis $r c(G)$, didefinisikan sebagai banyaknya warna minimal yang diperlukan untuk membuat graf $G$ bersifat rainbow connected. Misalkan $c$ adalah rainbow coloring dari graf terhubung $G$. Untuk dua titik $u$ dan $v$ di $G$, rainbow $u-v$ geodesic pada $G$ adalah rainbow $u-v$ path yang panjangnya $d(u, v)$ dimana $d(u, v)$ adalah jarak antara $u$ dan $v$ (panjang $u-v$ path terpendek di $(G)$. Graf $G$ dikatakan strongly rainbow connected jika $G$ memiliki suatu rainbow $u-v$ geodesic untuk setiap dua titik $u$ dan $v$ di $G$. Minimum $k$ yang terdapat pada pewarnaan $c: E(G) \rightarrow\{1,2, \cdots, k\}$ sedemikian sehingga $G$ adalah strongly rainbow connected dikatakan bilangan strong rainbow connection, $\operatorname{src}(G)$, di $G$. Jadi, $r c(G) \leq \operatorname{src}(G)$ untuk setiap graf terhubung di $G$. Pada paper ini akan dikaji kembali tentang bilangan strong rainbow connection untuk graf Garis, graf Middle dan graf Total dari Graf Matahari, seperti yang telah dibahas dalam [1].
\end{abstract}

Kata Kunci: Bilangan Strong Rainbow Connection, graf Garis, graf Middle, graf Total, graf Matahari

\section{Pendahuluan}

Konsep rainbow connection pada suatu graf pertama kali diperkenalkan oleh Chartrand, Johns, McKeon dan Zhang [3]. Misalkan $G=(V(G), E(G))$ adalah suatu graf terhubung tak trivial. Definisikan pewarnaan $c: E(G) \rightarrow\{1,2, \cdots, k\}, k \in N$, dimana dua sisi yang bertetangga boleh berwarna sama. Suatu lintasan $u-v$ path $P$ di $G$ dinamakan rainbow path jika tidak terdapat dua sisi di $P$ yang berwarna sama. Graf $G$ disebut rainbow connected jika setiap dua titik yang berbeda di $G$ dihubungkan oleh rainbow path.

Pewarnaan sisi yang menyebabkan $G$ bersifat rainbow connected dikatakan rainbow coloring. Jelas jika $G$ adalah rainbow connected, maka $G$ terhubung. Sebaliknya, setiap graf terhubung memiliki pewarnaan sisi trivial sehingga $G$ bersifat rainbow connected, yaitu setiap sisi diwarnai dengan warna berbeda. Bilangan rainbow connection dari graf terhubung $G$, ditulis $r c(G)$, didefinisikan sebagai banyaknya warna 
minimal yang diperlukan untuk membuat graf $G$ bersifat rainbow connected. Suatu rainbow coloring yang menggunakan sebanyak $r c(G)$ warna dikatakan minimum rainbow coloring.

Misalkan $c$ adalah rainbow coloring dari graf terhubung $G$. Untuk dua titik $u$ dan $v$ di $G$, rainbow $u-v$ geodesic pada $G$ adalah rainbow $u-v$ path yang panjangnya $d(u, v)$ dimana $d(u, v)$ adalah jarak antara $u$ dan $v$ (panjang $u-v$ path terpendek di $(G)$. Graf $G$ dikatakan strongly rainbow connected jika $G$ memiliki suatu rainbow $u-v$ geodesic untuk setiap dua titik $u$ dan $v$ di $G$. Dalam kasus ini, pewarnaan $c$ dikatakan strong rainbow coloring di $G$. Minimum $k$ yang terdapat pada pewarnaan $c: E(G) \rightarrow\{1,2, \cdots, k\}$ sedemikian sehingga $G$ adalah strongly rainbow connected dikatakan bilangan strong rainbow connection atau strong rainbow connection number, $\operatorname{src}(G)$, di $G$. Suatu strong rainbow coloring di $G$ yang menggunakan $\operatorname{src}(G)$ warna dikatakan minimum strong rainbow coloring di $G$. Jadi, $\operatorname{rc}(G) \leq \operatorname{src}(G)$ untuk setiap graf terhubung di $G$ [3]. Selanjutnya, jika $G$ adalah graf terhubung tak trivial dengan ukuran $m$ dan $\operatorname{diam}(G)=\max \{d(u, v) \mid u, v \in V(G)\}$, maka

$$
\operatorname{diam}(G) \leq r c(G) \leq \operatorname{src}(G) \leq m .
$$

Pada paper ini akan dikaji kembali tentang bilangan strong rainbow connection untuk graf Garis, graf Middle, dan graf Total untuk Graf Matahari, seperti yang telah dibahas pada [1].

\section{Bilangan Strong Rainbow Connection}

Berikut disajikan kembali proposisi yang membahas tentang graf $G$ dengan ukuran $m$ yang mempunyai nilai $\operatorname{rc}(G)$ dan $\operatorname{src}(G) 1,2$ dan $m$.

Proposisi 2.1. [3] Misalkan $G$ suatu graf terhubung tak trivial berukuran m. Maka berlaku:

(1) $\operatorname{rc}(G)=\operatorname{src}(G)=1$ jika dan hanya jika $G$ suatu graf lengkap.

(2) $\operatorname{rc}(G)=2$ jika dan hanya jika $\operatorname{src}(G)=2$.

(3) $\operatorname{rc}(G)=\operatorname{src}(G)=m$ jika dan hanya jika $G$ suatu graf pohon.

Proposisi 2.2. [3] Misalkan $C_{n}$ adalah graf lingkaran dengan banyak titik $n$, dimana $n \geq 4$ maka

$$
r c\left(C_{n}\right)=\operatorname{src}\left(C_{n}\right)=\left\lceil\frac{n}{2}\right\rceil .
$$

Teorema berikut menyajikan bilangan rainbow connection dan bilangan strong rainbow connection untuk graf Matahari.

Teorema 2.3. [1] Jika $n \geq 3$, maka

$$
r c\left(S_{n}\right)=\operatorname{src}\left(S_{n}\right)= \begin{cases}n, & \text { jika } n \text { ganjil } \\ \frac{3 n-2}{2}, & \text { jika } n \text { genap. }\end{cases}
$$

Bukti. Misalkan terdapat graf matahari $S_{n}$ dengan

$$
\begin{aligned}
& V\left(S_{n}\right)=\left\{v_{1}, \cdots, v_{n}, u_{1}, \cdots, u_{n}\right\}, \\
& E\left(S_{n}\right)=\left\{e_{i}^{\prime} \mid 1 \leq i \leq n\right\} \cup\left\{e_{i} \mid 1 \leq i \leq n-1\right\} \cup\left\{e_{n}\right\},
\end{aligned}
$$


dimana $\left\{v_{1}, \cdots, v_{n}\right\}$ adalah himpunan titik-titik graf lingkaran $C_{n} \operatorname{dan}\left\{u_{1}, \cdots, u_{n}\right\}$ adalah himpunan titik-titik pendant dari graf Matahari $S_{n}$ sedemikian sehingga $v_{i} u_{i}$ adalah sisi pendant, sisi $e_{i}$ adalah sisi $v_{i} v_{i+1}$ untuk $(1 \leq i \leq n-1)$, sisi $e_{n}$ adalah sisi $v_{n} v_{l}$ dan sisi $e_{i}^{\prime}$ adalah $v_{i} u_{i}(1 \leq i \leq n)$.

Pandang beberapa kasus berikut.

Kasus 1. Untuk $n$ ganjil.

Karena semua lintasan dari $u_{i}$ ke $v_{j}$ dari $1 \leq i \leq n$ dan $1 \leq j \leq n$ terhubung dengan sisi pendant $e_{i}^{\prime}$ dapat dilihat bahwa warna dari sisi $e_{i}^{\prime}$ harus berbeda yaitu $c\left(e_{i}^{\prime}\right)=\mathrm{i}$ untuk $1 \leq i \leq n$. oleh sebab itu

$$
\operatorname{rc}\left(S_{n}\right) \geq n \text {. }
$$

Sekarang kita lihat rainbow connection antara dua titik dari $S_{n}$, warna dari sisi lingkaran adalah $c\left(e_{(i+2)(\bmod n)}\right)=i$ untuk $1 \leq i \leq n$. Dapat dilihat bahwa

$$
r c\left(S_{n}\right) \leq n
$$

Dari (2.1) dan (2.2) dapat dilihat bahwa $r c\left(S_{n}\right)=\operatorname{src}\left(S_{n}\right)=n$. Pada Gambar 1 berikut diberikan ilustrasi untuk $S_{5}$.

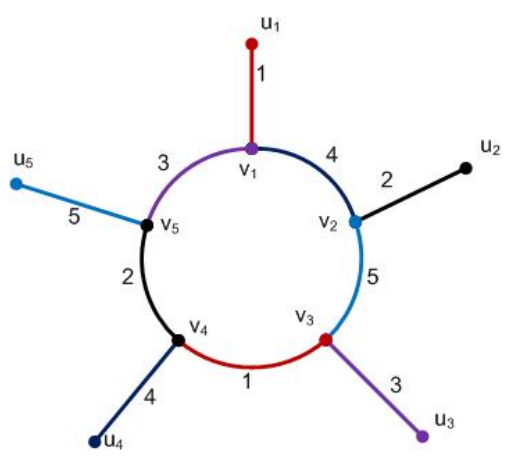

Gambar 1. $r c\left(S_{5}\right)=\operatorname{scr}\left(S_{5}\right)=5$

Kasus 2. Untuk $n$ genap.

Berdasarkan Kasus 1, misalkan $c\left(e_{i}^{\prime}\right)=i$ untuk $1 \leq i \leq n$. Definisikan suatu pewarnaan pada sisi lingkaran sebagai berikut.

$$
c\left(e_{i}\right)= \begin{cases}\frac{i}{2}+1, & \text { untuk } i=n \\ 2 i, & \text { untuk } i=\frac{n}{2} \\ i+n, & \text { untuk } 1 \leq i \leq \frac{n}{2}-1 \\ 1+\frac{n}{2}, & \text { untuk } \frac{n}{2}+1 \leq i \leq n-1 .\end{cases}
$$

Pada Gambar 2 berikut diberikan ilustrasi untuk graf $S_{4}$.

Berdasarkan definisi pewarnaannya, maka untuk $n=4,6,8, \cdots$ diperoleh bahwa

$$
r c\left(S_{n}\right)=\operatorname{src}\left(S_{n}\right)=5,8,11, \cdots .
$$

Pada Teorema 2.4 berikut diberikan bilangan rainbow connection dari graf garis dari graf Matahari. 


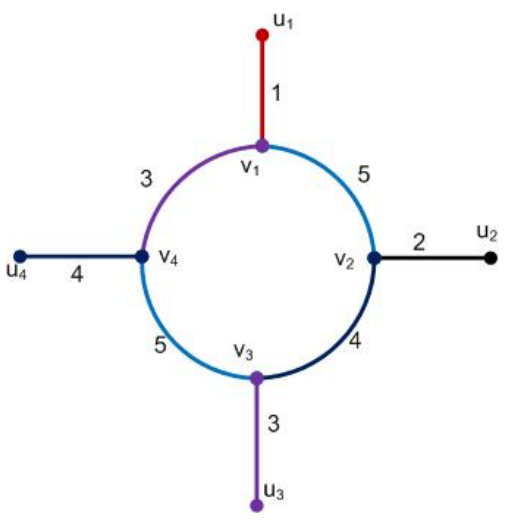

Gambar 2. $\operatorname{rc}\left(S_{4}\right)=\operatorname{src}\left(S_{4}\right)=5$

Teorema 2.4. [1] Jika $n \geq 3$, dan $G \simeq L\left(S_{n}\right)$, maka

$$
r c(G)=\operatorname{src}(G)= \begin{cases}2, & \text { untuk } n=3, \\ 3, & \text { untuk } n=4, \\ 4, & \text { untuk } n=5 \text { an } 6, \\ \left\lceil\frac{n}{2}\right\rceil+2, & \text { untuk } n \geq 7 .\end{cases}
$$

Bukti. Graf garis dari suatu $G$ adalah graf dengan $V(L(G))=E(G)$, dan dua titik $x, y \in E(G)$ adalah bertetangga di $L(G)$ jika dan hanya jika $x, y$ mempunyai tepat satu titik bersama di $G$. Himpunan titik dan sisi dari $S_{n}$ seperti pada Teorema 2.3. Karena $G \simeq L\left(S_{n}\right)$ maka

$$
V(G)=E\left(S_{n}\right)=\left\{u_{i}^{\prime} \mid 1 \leq i \leq n\right\} \cup\left\{v_{i}^{\prime}: 1 \leq i \leq n-1\right\} \cup\left\{v_{n}^{\prime}\right\},
$$

dimana $v_{i}^{\prime}$ dan $u_{i}^{\prime}$ masing-masing mewakili sisi $e_{i}$ dan $e_{i}^{\prime}$ untuk $1 \leq i \leq n$. Perhatikan kasus-kasus berikut.

Kasus 1. Untuk $n=3$.

Definisikan pewarnaan pada sisi-sisi $c: E(G) \longrightarrow\{1,2\}$ sebagai berikut

$$
\begin{aligned}
c\left(v_{1}^{\prime} v_{2}^{\prime}\right) & =c\left(v_{2}^{\prime} v_{3}^{\prime}\right)=c\left(v_{3}^{\prime} v_{1}^{\prime}\right)=1, \\
c\left(v_{i}^{\prime} u_{i}^{\prime}\right) & =1, \quad \text { untuk } 1 \leq i \leq 3, \\
c\left(v_{i}^{\prime} v_{i+1}^{\prime}\right) & =2, \text { untuk } 1 \leq i \leq 2, \\
c\left(v_{3}^{\prime} u_{1}^{\prime}\right) & =2 .
\end{aligned}
$$

Pada Gambar 3 diberikan ilustrasi untuk $L\left(S_{3}\right)$, dimana diperoleh bahwa $r c\left(L\left(S_{3}\right)\right)=\operatorname{src}\left(L\left(S_{3}\right)\right)=2$.

Kasus 2. Untuk $n=4$. 


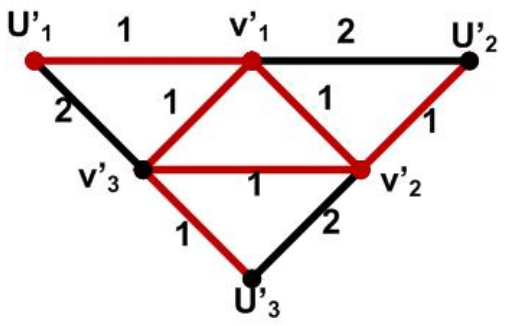

Gambar 3. $r c\left(L\left(S_{3}\right)\right)=\operatorname{src}\left(L\left(S_{3}\right)\right)=2$

Definisikan pewarnaan pada sisi-sisi $c: E(G) \longrightarrow\{1,2,3\}$ sebagai berikut.

$$
\begin{aligned}
c\left(v_{i}^{\prime} v_{i+1}^{\prime}\right) & = \begin{cases}1, & \text { jika } i \text { ganjil dan } 1 \leq i \leq 3, \\
2, & \text { jika } i \text { genap dan } 1 \leq i \leq 3,\end{cases} \\
c\left(v_{i}^{\prime} u_{i+1}^{\prime}\right) & = \begin{cases}1, & \text { jika } i \text { ganjil dan } 1 \leq i \leq 3, \\
2, & \text { jika } i \text { genap dan } 1 \leq i \leq 3,\end{cases} \\
c\left(v_{n}^{\prime} u_{1}^{\prime}\right) & =2, \\
c\left(v_{i}^{\prime} v_{i+1}^{\prime}\right) & =1, \quad \text { untuk } 1 \leq i \leq 4, \\
c\left(v_{n}^{\prime} v_{l}^{\prime}\right) & =1, \quad \text { untuk } 1 \leq i \leq 4 .
\end{aligned}
$$

Pada Gambar 4 diberikan ilustrasi untuk $L\left(S_{4}\right)$, dimana diperoleh bahwa $r c\left(L\left(S_{4}\right)\right)=\operatorname{src}\left(L\left(S_{4}\right)\right)=3$.

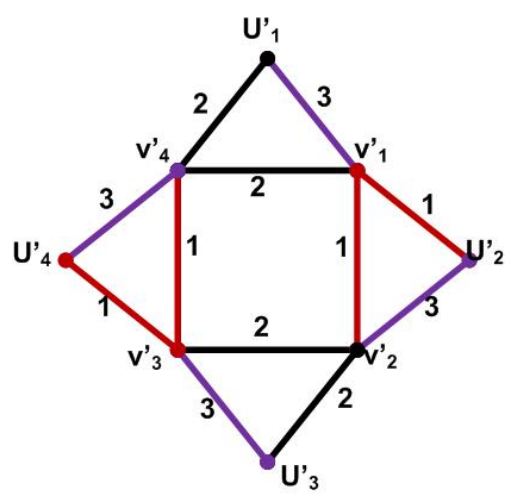

Gambar 4. $r c\left(L\left(S_{4}\right)\right)=\operatorname{src}\left(L\left(S_{4}\right)\right)=3$

Kasus 3. Untuk $n=5$. 
Definisikan pewarnaan pada sisi-sisi $c: E(G) \longrightarrow\{1,2,3,4\}$ sebagai berikut.

$$
\begin{aligned}
c\left(v_{i}^{\prime} v_{i+1}^{\prime}\right) & =(i+1)(\bmod 3), \quad \text { untuk } 1 \leq i \leq 4, \\
c\left(v_{n}^{\prime} v_{l}^{\prime}\right) & =1, \\
c\left(v_{i}^{\prime} u_{i}^{\prime}\right) & =i(\bmod 3), \quad \text { untuk } 1 \leq i \leq 5, \\
c\left(v_{i}^{\prime} u_{i+1}^{\prime}\right) & =4, \quad \text { untuk } 1 \leq i \leq 4, \text { dan } \\
c\left(v_{5}^{\prime} u_{l}^{\prime}\right) & =4 .
\end{aligned}
$$

Pada Gambar 5 diberikan ilustrasi untuk $L\left(S_{5}\right)$. Karena $\operatorname{diam}\left(L\left(S_{5}\right)\right)=3$ tidak cukup untuk membuat $\left(L\left(S_{5}\right)\right.$ menjadi $r c\left(L\left(S_{5}\right)\right)$ dan $\operatorname{src}\left(L\left(S_{5}\right)\right)$, maka $r c\left(L\left(S_{5}\right)\right)=$ $\operatorname{src}\left(L\left(S_{5}\right)\right)=4$.

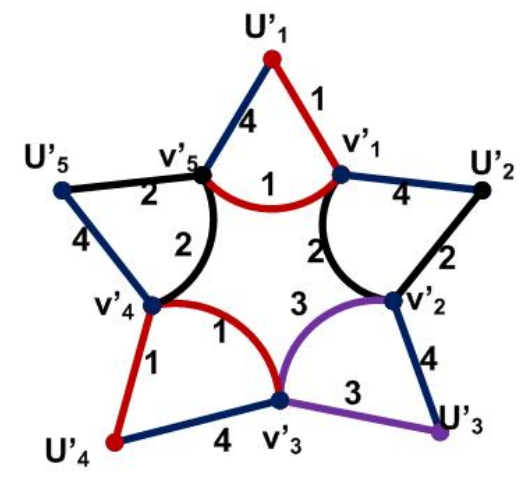

Gambar 5. $r c\left(L\left(S_{5}\right)\right)=\operatorname{src}\left(L\left(S_{5}\right)\right)=4$

Kasus 4. Untuk $n=6$.

Definisikan pewarnaan pada sisi-sisi $c: E(G) \longrightarrow\{1,2,3,4\}$ sebagai berikut.

$$
\begin{aligned}
c\left(v_{i}^{\prime} v_{i+1}^{\prime}\right) & =i(\bmod 3), \quad \text { untuk } 1 \leq i \leq 5, \\
c\left(v_{n}^{\prime} v_{l}^{\prime}\right) & =3, \\
c\left(v_{i+1}^{\prime} u_{i+1}^{\prime}\right) & =i(\bmod 3), \quad \text { untuk } 1 \leq i \leq 5, \\
c\left(v_{1}^{\prime} u_{1}^{\prime}\right) & =3, \\
c\left(v_{i}^{\prime} u_{i+1}^{\prime}\right) & =4, \quad \text { untuk } 1 \leq i \leq 5, \text { dan } \\
c\left(v_{6}^{\prime} u_{l}^{\prime}\right) & =4 .
\end{aligned}
$$

Pada Gambar 6 diberikan ilustrasi untuk $L\left(S_{6}\right)$, dimana diperoleh bahwa $r c\left(L\left(S_{6}\right)\right)=\operatorname{src}\left(L\left(S_{6}\right)\right)=4$.

Kasus 5. Untuk $n=7$.

Misalkan

$$
V\left(C_{n}\right)=\left\{v_{1}^{\prime}, v_{2}^{\prime}, \cdots, v_{n}^{\prime}, v_{n+1}^{\prime}\right\}=v_{i}^{\prime} \text { untuk } i=1,2, \cdots, n .
$$




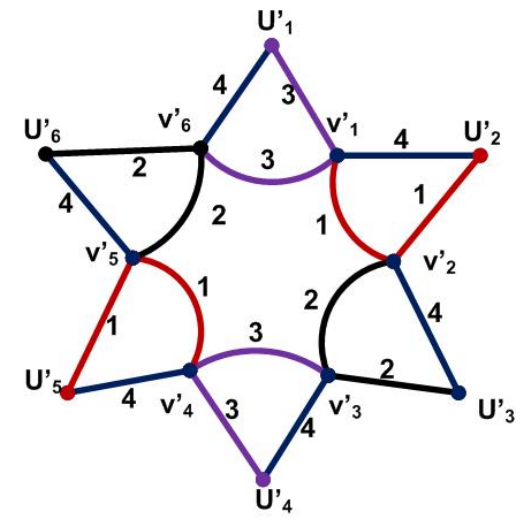

Gambar 6. $r c\left(L\left(S_{6}\right)\right)=\operatorname{src}\left(L\left(S_{6}\right)\right)=4$

Definisikan pewarnaan sisi-sisi dari lingkaran $e_{i}=v_{i}^{\prime} v_{i+1}^{\prime}$ sebagai berikut

$$
\begin{aligned}
& c\left(e_{i}\right)= \begin{cases}i, & \text { untuk } 1 \leq i \leq\left\lceil\frac{n}{2}\right\rceil, \\
i-\left\lceil\frac{n}{2}\right\rceil, & \text { untuk }\left\lceil\frac{n}{2}\right\rceil+1 \leq i \leq n,\end{cases} \\
& c\left(v_{n}^{\prime} v_{l}^{\prime}\right)=2 \text {, } \\
& c\left(v_{i}^{\prime} u_{i}^{\prime}\right)=\left\lceil\frac{n}{2}\right\rceil+1, \quad \text { untuk } 1 \leq i \leq n, \\
& c\left(v_{i}^{\prime} u_{(i+1)(\bmod n)}^{\prime}=\left\lceil\frac{n}{2}\right\rceil+2, \quad \text { untuk } 1 \leq i \leq n .\right.
\end{aligned}
$$

Berdasarkan penjelasan diatas, maka diperoleh bahwa $r c(L(G))=\operatorname{src}(L(G))=$ $\left\lceil\frac{n}{2}\right\rceil+2$.

Pada Teorema 2.5 berikut diberikan bilangan rainbow connection dari graf middle dari graf Matahari.

Teorema 2.5. [1] Jika $n \geq 3$, dan $G \simeq M\left(S_{n}\right) \operatorname{maka} r c(G)=\operatorname{src}(G)=n+1$.

Bukti. Graf middle dari suatu graf $G$ adalah graf dengan himpunan titik $V(M(G))=V(G) \cup E(G)$, dan himpunan sisi dengan syarat sebagai berikut. Jika $x y \in E(M(G))$, maka salah satu dari pernyataan berikut terpenuhi:

(1) $x, y$ di $E(G)$ dan $x, y$ bertetangga di $G$.

(2) $x$ di $V(G), y$ di $E(G)$, dan $x, y$ terkait di $G$.

Himpunan titik dan sisi dari $S_{n}$ seperti pada Teorema 2.3. Karena $G \simeq M\left(S_{n}\right)$, maka

$V(G)=V\left(S_{n}\right) \cup E\left(S_{n}\right)=\left\{v_{i} \mid 1 \leq i \leq n\right\} \cup\left\{u_{i} \mid 1 \leq i \leq n\right\} \cup\left\{v_{i}^{\prime} \mid 1 \leq i \leq n\right\} \cup\left\{u_{i}^{\prime} \mid 1 \leq i \leq n\right\}$,

dimana $v_{i}^{\prime}$ dan $u_{i}^{\prime}$ masing-masing mewakili sisi $e_{i}$ dan $e_{i}^{\prime}$, untuk $1 \leq i \leq n$. 
Definisikan pewarnaan sisi-sisi dari graf middle sebagai berikut

$$
\begin{aligned}
c\left(u_{i}^{\prime} u_{i}\right) & =i, 1 \leq i \leq n, \\
c\left(v_{i}^{\prime} u_{i}^{\prime}\right) & =n+1,1 \leq i \leq n, \\
c\left(v_{i+1} u_{i+1}^{\prime}\right) & =i, 1 \leq i \leq n-1, \\
c\left(v_{1} u_{1}^{\prime}\right) & =n \\
c\left(v_{i}^{\prime} u_{i+1}^{\prime}\right) & =(i+2)(\bmod n), 1 \leq i \leq n-1, \\
c\left(v_{n}^{\prime} u_{1}^{\prime}\right) & =2 \\
c\left(v_{i} v_{i}^{\prime}\right) & =i, 1 \leq i \leq n, \\
c\left(v_{i}^{\prime} v_{i+1}\right) & =i+1,1 \leq 1 \leq n-1, \\
c\left(v_{n}^{\prime} v_{1}\right) & =1 \\
c\left(v_{i}^{\prime} v_{i+1}^{\prime}\right) & =i+1,1 \leq i \leq n-1, \\
c\left(v_{n}^{\prime} u_{1}^{\prime}\right) & =1 .
\end{aligned}
$$

Pada Gambar 7 diberikan ilustrasi untuk $M\left(S_{5}\right)$. Diperoleh bahwa $\operatorname{rc}\left(M\left(S_{5}\right)\right)=$ $\operatorname{src}\left(M\left(S_{5}\right)\right)=n+1$.

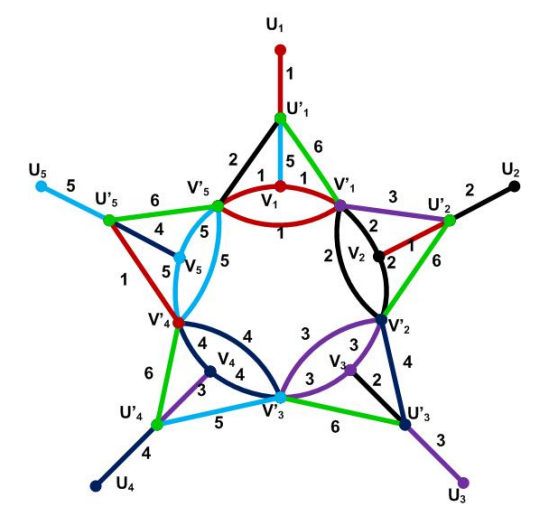

Gambar 7. $r c\left(M\left(S_{5}\right)\right)=\operatorname{scr}\left(M\left(S_{5}\right)\right)=6$

Pada Teorema 2.6 berikut diberikan bilangan rainbow connection dari graf total dari graf Matahari.

Teorema 2.6. [1] Jika $n \geq 3$ dan $G \simeq T\left(S_{n}\right)$, maka

$$
r c\left(S_{n}\right)=\operatorname{src}\left(S_{n}\right)= \begin{cases}n, & \text { jika } n \text { ganjil } \\ n+1, & \text { jika } n \text { genap }\end{cases}
$$

Bukti. Graf total dari suatu graf $G$ adalah graf dengan $V(T(G))=V(G) \cup E(G)$, dan himpunan sisi dengan syarat sebagai berikut. Jika $x y \in E(T(G))$, maka salah satu dari pernyataan berikut terpenuhi. 
(1) $x, y$ di $V(G)$ dan $x$ bertetangga dengan $y$ di $G$.

(2) $x, y$ di $E(G)$ dan $x, y$ bertetangga di $G$.

(3) $x$ di $V(G), y$ di $E(G)$, dan $x, y$ terkait di $G$.

Himpunan titik dan sisi dari $S_{n}$ seperti pada Teorema 2.3. Karenan $G \simeq T\left(S_{n}\right)$, maka

$V(G)=V\left(S_{n}\right) \cup E\left(S_{n}\right)=\left\{v_{i} \mid 1 \leq i \leq n\right\} \cup\left\{v_{i}^{\prime} \mid 1 \leq i \leq n\right\} \cup\left\{u_{i} \mid 1 \leq i \leq n\right\} \cup\left\{u_{i}^{\prime} \mid 1 \leq i \leq n\right\}$,

dimana $v_{i}^{\prime}$ dan $u_{i}^{\prime}$ masing-masing mewakili sisi $e_{i}$ dan $e_{i}^{\prime}$, untuk $1 \leq i \leq n$.

Pandang beberapa kasus berikut.

Kasus 1. Untuk $n$ ganjil.

Definisikan pewarnaan untuk sisi-sisi graf total sebagai berikut.

$$
\begin{aligned}
c\left(v_{i} u_{i}\right) & =i, 1 \leq i \leq n, \\
c\left(v_{i}^{\prime} u_{i}^{\prime}\right) & =i, 1 \leq i \leq n, \\
c\left(v_{i} u_{i}^{\prime}\right) & =i, 1 \leq i \leq n-1, \\
c\left(v_{i}^{\prime} u_{i+1}^{\prime}\right) & =i+1, \quad 1 \leq i \leq n-1, \\
c\left(v_{n}^{\prime} u_{1}^{\prime}\right) & =1, \\
c\left(u_{i}^{\prime} u_{i}\right) & =(i+2)(\bmod n), 1 \leq i \leq n, \\
c\left(v_{i} v_{i}^{\prime}\right) & =i, 1 \leq i \leq n, \\
c\left(v_{i}^{\prime} v_{i+1}\right) & =i+1, \quad 1 \leq i \leq n-1, \\
c\left(v_{n}^{\prime} v_{1}\right) & =1, \\
c\left(v_{i}^{\prime} v_{i+1}^{\prime}\right) & =i+1,1 \leq i \leq n-1, \\
c\left(v_{n}^{\prime} v_{1}^{\prime}\right) & =1, \\
c\left(v_{i} v_{i+1}\right) & =(i+2)(\bmod n), 1 \leq 1 \leq n-1 . \\
c\left(v_{n} v_{1}\right) & =n-2 .
\end{aligned}
$$

Pada Gambar 8 diberikan ilustrasi untuk $T\left(S_{5}\right)$, diperoleh bahwa $r c\left(T\left(S_{5}\right)\right)=$ $\operatorname{scr}\left(T\left(S_{5}\right)\right)=5$.

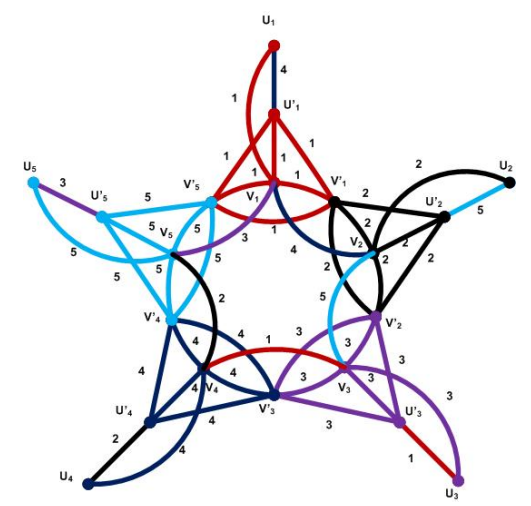

Gambar 8. $r c\left(T\left(S_{5}\right)\right)=\operatorname{scr}\left(T\left(S_{5}\right)\right)=5$ 
Kasus 2. Untuk $n$ genap.

Definisikan pewarnaan untuk sisi-sisi graf total sebagai berikut.

$$
\begin{aligned}
c\left(v_{i} u_{i}\right) & =i, 1 \leq i \leq n, \\
c\left(u_{i}^{\prime} u_{i}\right) & =i, 1 \leq i \leq n, \\
c\left(v_{i}^{\prime} u_{i}^{\prime}\right) & =n+1,1 \leq i \leq n, \\
c\left(v_{i+1} u_{i+1}^{\prime}\right) & =i, 1 \leq i \leq n-1, \\
c\left(v_{1} u_{1}^{\prime}\right) & =n, \\
c\left(v_{i}^{\prime} u_{i+1}^{\prime}\right. & =(i+2)(\bmod n), 1 \leq i \leq n-1, \\
c\left(v_{n}^{\prime} u_{1}^{\prime}\right) & =2 . \\
c\left(v_{i} v_{i}^{\prime}\right. & =i, 1 \leq i \leq n, \\
c\left(v_{i}^{\prime} v_{i+1}^{\prime}\right) & =i+1,1 \leq i \leq n-1, \\
c\left(v_{n}^{\prime} v^{\prime} 1\right) & =1 \\
c\left(v_{i} v_{i+1}\right) & =(i+4)(\bmod n), 1 \leq 1 \leq n-1, \\
c\left(v_{n} v_{1}\right) & =n-2, \\
c\left(v_{i}^{\prime} v_{i+1}\right) & =i+1, \\
c\left(v_{n}^{\prime} v_{1}\right) & =1 \\
c\left(v_{i}^{\prime} u_{i}^{\prime}\right) & =n+1 .
\end{aligned}
$$

Pada Gambar 9 diberikan ilustrasi untuk $T\left(S_{6}\right)$, diperoleh bahwa $\operatorname{rc}\left(T\left(S_{6}\right)\right)=$ $\operatorname{scr}\left(T\left(S_{6}\right)\right)=6+1$.

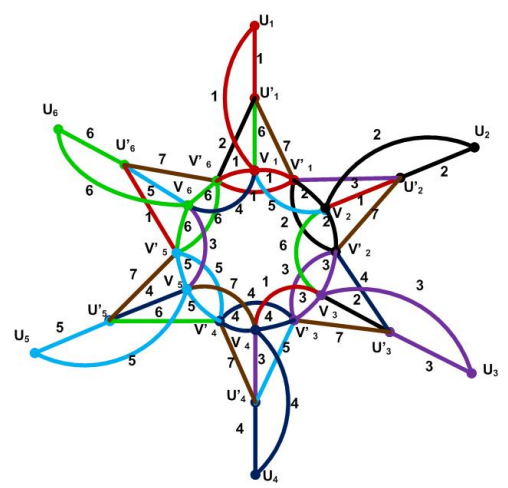

Gambar 9. $r c\left(T\left(S_{6}\right)\right)=\operatorname{scr}\left(T\left(S_{6}\right)\right)=7$

\section{Kesimpulan}

Pada tulisan ini telah dikaji kembali tentang diperoleh bilangan rainbow connection dan bilangan strong rainbow connection untuk graf matahari. Selanjutnya diperoleh 
bilangan rainbow connection dan bilangan strong rainbow connection untuk graf garis, graf middle dan graf total dari graf matahari.

\section{Ucapan Terima Kasih}

Penulis mengucapkan terima kasih kepada Bapak Prof. Dr. Syafrizal Sy, Ibu Dr. Lyra Yulianti, Bapak Dr. Muhafzan, Bapak Dr. Admi Nazra dan Bapak Dr. Mahdhivan Syafwan yang telah memberikan masukan dan saran, sehingga tulisan ini dapat diselesaikan dengan baik, dan dapat dipublikasikan.

\section{Daftar Pustaka}

[1] K. Srinivasa Reo dan R. Murali, 2015. Rainbow Connection Numbers of Sunlet Graph and Its Line, Middle and Total Graph, International Journal of Mathematics and Its Applications 3 (4A): 105 - 113.

[2] Chartrand, G. dan P. Zhang, 2005. Introduction to Graph Theory, McGraw-Hill International Editions, Singapore.

[3] Chartrand, G. dkk, 2008. Rainbow Connection in Graphs, Math. Bohem. 133: $85-98$.

[4] Yuefang Sun, 2013. Rainbow Connection Numbers of Line Graphs, Middle Graphs and Total Graphs, International Journal of Applications Mathematics and Statistics. 42(12) : $361-369$.

[5] Syafrizal Sy, Gema Histamedika dan Lyra Yulianti, 2013. Rainbow Connection Numbers of Fan and Sun, Applied Mathematical Sciences 7 : 3155 - 3159.

[6] Xveliang Li and Yuefang Sun, 2011. Rainbow Connection Number of Line Graphs, Ars Combin. 100 : $449-463$.

[7] Diestel, R., 2010. Graph Theory, Springer. 